\section{Global Proceedings Repository \\ American Research Foundation}

ISSN 2476-017X

Available online at http:// proceedings.sriweb.org

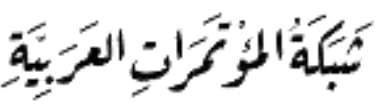

http://arab.kmshare.net/

The 1st International Conference on Sciences and Arts (ICMSA 2017)

$$
3 \text { مايو } 2017 \text { - اربيل - العراقتمر الدولي الاول للعلوم والاداب } 2
$$

\title{
Contra And Perfectly Contra T* - Intuitionistic Generalized - Irresolute Maps On Intuitionistic Topological Spaces
}

\author{
Asmaa Ghasoob Raoof \\ Dept of mathematic/ college of Education/ Tikrit university
}

\begin{abstract}
In this paper,I introduce a new class of maps(contra $\mathrm{T}^{*}$-intuitionistic generalized irresolute maps) in intuitionistic topological spaces,some of its properties and relations are studied .Through this concept I introduce a new class of maps(perfectly contra $\mathrm{T}^{*}$-intuitionistic generalized irresolute maps)in intuitionistic topological spaces .Also I introduce several kinds of perfectly contra $\mathrm{T}^{*}$-intuitionistic generalized irresolute map and Istudy some of their properties and relation among them.
\end{abstract}

Key words: Contra $\mathrm{T}^{*}$-intuitionistic generalized irresolute maps in intuitionistic topological spaces, perfectly contra $\mathrm{T}^{*}$-intuitionistic generalized irresolute maps in intuitionistic topological spaces .

\section{I- Introduction}

Dunham,W. [5] introduced generalized closure operator $\mathrm{cl}^{*}$ and defined a topology called $\mathrm{T}^{*}$ topology .Sakthive, K.[15] introduced and studied intuitionistic fuzzy Alpha generalized continuous maps and intuitionistic Alpha generalized irresolute maps. Pushpalatha, A. Eswaran, S. and Rajar,P.[10] studied and investigated T*generalized closed sets .Eswaran, S.and Pushpalatha, A.[6] introduced T"generalized-continuous maps in topological spaces.Pushpalatha, A. and Eswaran, S. [11] defined two classes of maps called perfectly generalized-continuous maps and strongly $\mathrm{T}^{*}$ generalized- 


\section{Global Proceedings Repository American Research Foundation}

ISSN 2476-017X

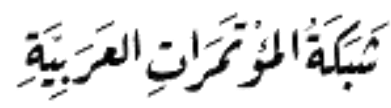

http://arab.kmshare.net/

Available online at http:// proceedings.sriweb.org

continuous maps respectively. Raouf, G. A. and Yaseen , Y. J. [12] studied contra and totally $\mathrm{T}^{*}$ - intuitionistic generalized continuous maps and some kinds in intuitionistic in intuitionistic topological spaces . Miguel ,Caldas , C. [9] have defined perfectly contra irresolute maps and studied weak and strong forms of irresolute. In this paper I introduce two new classes of maps between intuitionistic topological spaces(ITS) namely contra $\mathrm{T}^{*}$ intuitionistic generalized- irresolute maps, perfectly contra $\mathrm{T}^{*}$-intuitionistic generalizedirresolute maps in intuitionistic topological spaces and some kinds in intuitionistic topological spaces and study their properties. Throughout this paper $\left(\mathrm{X}, \mathrm{T}^{*}\right)$ and $\left(\mathrm{Y}, \mathrm{T}^{*}\right)$ (or simply X and Y )represent non- empty intuitionistic topological spaces (ITS) on which no separation axioms are assumed, unless otherwise mentioned. Let $\mathrm{A}$ be an IS in (X, T*), I denote the closure of A (respectively the generalized closure operator is defined by the intersection of all Ig-closed contining $\mathrm{A}$, and $\mathrm{A}^{\mathrm{c}}$ represent closure of $\mathrm{A}$ and complement of A to an intuitionistic topological spaces (ITS) on $\mathrm{T}^{*}$ by cl (A)(respectively cl* (A)) .

\section{II-Preliminaries}

I recall the following definitions which are needed in our work .

Let $X$ be a non-empty set, and let $A$ and $B$ be IS having the form $A=\left\langle x, A_{1}, A_{2}\right\rangle$;

$\mathrm{B}=\left\langle\mathrm{x}, \mathrm{B}_{1}, \mathrm{~B}_{2}\right\rangle$ respectively. Furthermore, let $\left\{\mathrm{A}_{\mathrm{i}}: \mathrm{i} \in \mathrm{I}\right\}$ be an arbitrary family of IS in $\mathrm{X}$, where $A_{i}=\left\langle x, A_{i}^{(1)}, A_{i}^{(2)}\right\rangle$, then:

1) $\widetilde{\emptyset}=\langle\mathrm{x}, \emptyset, \mathrm{X}\rangle ; \widetilde{\mathrm{X}}=\langle\mathrm{x}, \mathrm{X}, \emptyset\rangle$.

2) $\mathrm{A} \subseteq \mathrm{B}$, iff $\mathrm{A}_{1} \subseteq \mathrm{B}_{1}$ and $\mathrm{A}_{2} \supseteq \mathrm{B}_{2}$.

3) The complement of $A$ is denoted by $\bar{A}$ and defined by $\bar{A}=\left\langle x, A_{2}, A_{1}\right\rangle$.

4) $\cup A_{i}=\left\langle x, \cup A_{i}^{(1)}, \cap A_{i}^{(2)}\right\rangle, \cap A_{i}=\left\langle x, \cap A_{i}^{(1)}, \cup A_{i}^{(2)}\right\rangle[3]$. Let $X$ and $Y$ be two non-empty sets and $\mathrm{f}: \mathrm{X} \rightarrow \mathrm{Y}$ be a function. If $\mathrm{B}=\left\langle\mathrm{y}, \mathrm{B}_{1}, \mathrm{~B}_{2}\right\rangle$ is IS in $\mathrm{Y}$, then the preimage of $\mathrm{B}$ under $\mathrm{f}$ denoted by $f^{-1}(B)$ is IS in $X$ defined by $f^{-1}(B)=\left\langle x, f^{-1}\left(B_{1}\right), f^{-1}\left(B_{2}\right)\right\rangle$ [3] . An intuitionistic topology (IT, for short) on a non-empty set $X$, is a family $T$ of IS in $X$ containing $\widetilde{\emptyset}, \widetilde{X}$ and closed under arbitrary unions and finitely intersections. The pair $(\mathrm{X}, \mathrm{T})$ is called an intuitionistic topological space (ITS, for short) [3]. Let (X,T) be ITS and $A$ be asubset of $X$, then the interior and closure of $A$ are defined by int $(A)=U\{G i$ : Gi $\in \mathrm{T}, \mathrm{Gi} \subseteq \mathrm{A}\}, \operatorname{cl}(\mathrm{A})=\bigcap\left\{\mathrm{K}_{\mathrm{i}}: \mathrm{K}_{\mathrm{i}}\right.$ is ICS in $\mathrm{X}$ and $\left.\mathrm{A} \subseteq \mathrm{K}_{\mathrm{i}}\right\}$ [13]. A subset $\mathrm{A}$ of intuitionistic topological spaces(ITS, for short)(X, T)is said to be generalized closed(Igclosed)in $\mathrm{X}$ if $\operatorname{Icl}(\mathrm{A}) \subseteq$ Uwhenever $A \subseteq U$ and Uis Iopen in X.Asubset $A$ is called generalized open(Ig-open)in $X$ if its complement $\bar{A}$ is Ig-closed every Iclosed set is Igclosed [7]. Let $(X, T)$ and $(Y, \tau)$ be two ITS and Let $f: X \rightarrow Y$ be afunction, then $\mathrm{f}$ is said to be continuous if $\mathrm{f}^{-1}(\mathrm{~V})$ is I-closed (or I-open) in $\mathrm{X}$ for every y I-closed set (or I-open set) $\mathrm{V}$ in $\mathrm{Y}[3]$. Let $(\mathrm{X}, \mathrm{T})$ and $(\mathrm{Y}, \tau)$ be two ITS and Let $\mathrm{f}: \mathrm{X} \rightarrow \mathrm{Y}$ be afunction, then $\mathrm{f}$ is said to be irresolute if $f^{-1}(V)$ is Isemi-closed set in $X$ for every Isemi-closed set $V$ in $Y$ [9]. Let $(\mathrm{X}, \mathrm{T})$ and $(\mathrm{Y}, \tau)$ be two ITS and Let $\mathrm{f}: \mathrm{X} \rightarrow \mathrm{Y}$ be afunction, then $\mathrm{f}$ is said to be semiirresolute (resp. pre- irresolute, semipre- irresolute and presemi- irresolute) if $f^{-1}(V)$ is Isemi-closed (resp. Ipre-closed, Isemipre-closed and Ipresemi-closed )set in $\mathrm{X}$ for every Isemi-closed (resp. Ipre-closed, Isemipre-closed and Ipresemi-closed set V in Y [9]. A subset A of ITS (X, T) is said to be:- 1) gs-closed (resp. psg - closed, gsp - closed, if Iscl(A) $\subseteq \mathrm{U}($ resp. I $\operatorname{pscl}(\mathrm{A}) \subseteq \mathrm{U}$ and $\mathrm{Ispcl} \subseteq \mathrm{U}$ ) whenever $\mathrm{A} \subseteq \mathrm{U}$ and $\mathrm{U}$ is $\mathrm{I}$ open set in $X$. 2) sg - closed(resp.gps - closed ) if $I \operatorname{scl}(A) \subseteq U(\operatorname{resp}$. $\operatorname{Ipsc}(A) \subseteq U$ whenever $U$ is Isemi-open (resp. I presemi-open ) set in X [7]. A subset A of ITS (X, T) is said to be :- 


\section{Global Proceedings Repository American Research Foundation}

ISSN 2476-017X

Available online at http:// proceedings.sriweb.org

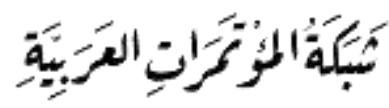

http://arab.kmshare.net/

a) An intuitionistic presemi-closed (Ips-closed) if $\operatorname{I~cl}(\operatorname{I~int~}(\operatorname{I~cl}(A))) \subseteq \mathrm{A}$.

b) An intuitionistic pre-closed (Ip-closed) if I $\operatorname{cl}(\operatorname{I} \operatorname{int}(\mathrm{A})) \subseteq \mathrm{A}$.

c) An intuitionistic semi-closed (Isemi-closed) if $\mathrm{I} \operatorname{int}(\mathrm{I} \operatorname{cl}(\mathrm{A})) \subseteq \mathrm{A}$.

d) An intuitionistic semipre-closed(Isp-closed) if $\operatorname{I} \operatorname{int}(\operatorname{I} \operatorname{cl}(\operatorname{I} \operatorname{int}(\mathrm{A}))) \subseteq \mathrm{A}[1]$. For the subset A of ITS $(X, T)$, the intuitionistic generalized closure operator $\mathrm{I} \mathrm{cl}^{*}$ is defined by the intersection of all I g-closed sets containing A[5]. For the subset A of ITS (X,T), the Isemi-closure (resp.I semipre-closure ,I presemi-closure ) of A is defined as the intersection of all I semi-closed set(resp. I semipre-closed set, I presemi-closed set containing $\mathrm{A}[5]$. A map $\mathrm{f}:(\mathrm{X}, \mathrm{T}) \rightarrow(\mathrm{Y}, \tau)$ is called generalized - irresolute (Ig- irresolute) (resp. generalized semi- irresolute, semi generalized- irresolute, generalized presemiirresolute, presemi generalized- irresolute and generalized semipre- irresolute)(resp. Igs irresolute, Isg- irresolute,Igps- irresolute,Ipsg- irresolute and Igsp- irresolute) if $\mathrm{f}^{-1}(\mathrm{~V})$ is Ig- closed(resp. Igs-closed,Isg-closed, Igps-closed,Ipsg-closed and Igsp-closed)set in X for every Ig- closed(resp. Igs-closed,Isg-closed, Igps-closed,Ipsg-closed and Igspclosed)set $\mathrm{V}$ set in $\mathrm{Y}$ [9]. A map $\mathrm{f:X} \rightarrow \mathrm{Y}$ from an intuitionistic topological space $(\mathrm{X}, \mathrm{T})$ in to an intuitionistic topological space $(Y, \tau)$ is called contra-continuous if $f^{-1}(V)$ is Iclosed set in $X$ for each Iopen $V$ set in $Y[5]$. A map $f: X \rightarrow Y$ from an intuitionistic topological space $(X, T)$ in to an intuitionistic topological space $(Y, \tau)$ is called contra irresolute if $\mathrm{f}^{-1}(\mathrm{~V})$ is Isemi-closed set in $\mathrm{X}$ for each Isemi-open $\mathrm{V}$ set in $\mathrm{Y}[9]$ ]. A map $\mathrm{f}: \mathrm{X} \rightarrow \mathrm{Y}$ from an intuitionistic topological space $(\mathrm{X}, \mathrm{T})$ in to an intuitionistic topological space $(\mathrm{Y}, \tau)$ is called contra semipre-irresolute (resp. contra pre- irresolute and contra presemiirresolute) (contra Isp- irresolute (resp. contra Ip- irresolute and contra Ips- irresolute) function if $\mathrm{f}^{-1}(\mathrm{~V})$ is Isp-closed(resp. Ip-closed and Ips-closed) set in $\mathrm{X}$ for each Ispopen(resp.Ip-open and Ips-open) $\mathrm{V}$ set in $\mathrm{Y}[2]$. A map $\mathrm{f}: \mathrm{X} \rightarrow \mathrm{Y}$ from an intuitionistic topological space $(\mathrm{X}, \mathrm{T})$ in to an intuitionistic topological space $(\mathrm{Y}, \tau)$ is called contra generalized-irresolute (resp. contra gs- irresolute, contra sg- irresolute, contra psgirresolute ,contra gps- irresolute and contra gsp- irresolute) function if $f^{-1}(V)$ is Ig-closed (resp. Igs-closed, Isg-closed, Ipsg-closed, Igps-closed and Igsp-closed) set in $\mathrm{X}$ for each Ig-open (resp. Igs-open, Isg-open, Ipsg-open, Igps-open and Igsp-open) set V in Y [2]. A subset $\mathrm{A}$ of ITS $(X, T)$, the topology $\mathrm{T}^{*}$ is defined by $\mathrm{T}^{*}=\left\{\mathrm{U}: \operatorname{Icl}^{*}(\overline{\mathrm{U}})=(\overline{\mathrm{U}})\right\}[10]$. A subset A of ITS $(X, T)$ is called $T^{*}$-generalized-closed sets( $T^{*}$-Ig-closed) if $\operatorname{Icl}^{*}(A) \subseteq U$ whenever $\mathrm{A} \subseteq \mathrm{U}$ and $\mathrm{U}$ is $\mathrm{T}^{*}$-I-open in X.The complement of $\mathrm{T}^{*}$-Igeneralized-closed set is called the $\mathrm{T}^{*}$-I generalized-open set ( $\mathrm{T}^{*}$-Ig-open) [10]. A collection $\left\{A_{\mathrm{i}}: i \in I\right\}$ of Ig-open sets in a topological space $(X, T)$ is called a Ig-open cover of a subset $B$ if $B \subset U\left\{A_{i}: i \in I\right\}[10]$. A map $f:(X, T) \rightarrow(Y, \tau)$ is called $T^{*}$ generalized-irresolute function if $\mathrm{f}^{-1}(\mathrm{~V})$ is $\mathrm{T}^{*}$-Ig-closed set in $\mathrm{X}$ for every $\mathrm{T}^{*}$-Ig-closed set $\mathrm{V}$ in $\mathrm{Y}[10]$.

A map $\mathrm{f}:(\mathrm{X}, \mathrm{T}) \rightarrow(\mathrm{Y}, \tau)$ is said to be contra generalized-continuous (contra Igcontinuous) if $\mathrm{f}^{-1}(\mathrm{~V})$ is Ig-closed set in $\mathrm{X}$ for every I-open set $\mathrm{V}$ in $\mathrm{Y}[2]$. A map $\mathrm{f}:(\mathrm{X}, \mathrm{T}) \rightarrow(\mathrm{Y}, \tau)$ is said to be perfectly generalized-continuous (perfectly Ig-continuous) if $\mathrm{f}^{-1}(\mathrm{~V})$ is both Iopen and I-closed set in $\mathrm{X}$ for every Ig-closed set $\mathrm{V}$ in $\mathrm{Y}[11]$. A map $\mathrm{f}:(\mathrm{X}, \mathrm{T}) \rightarrow(\mathrm{Y}, \tau)$ is called $\mathrm{T}^{*}$-generalized continuous ( $\mathrm{T}^{*}$-Ig-continuous) if $\mathrm{f}^{-1}(\mathrm{~V})$ is $\mathrm{T}^{*}$ Ig-closed set in $\mathrm{X}$ for every Ig-closed set in $\mathrm{Y}[11]$. A map $\mathrm{f}:(\mathrm{X}, \mathrm{T}) \rightarrow(\mathrm{Y}, \tau)$ is called called strongly $\mathrm{T}^{*}$ - generalized- continuous(strongly $\mathrm{T}^{*}$-Ig-continuous) if $\mathrm{f}^{-1}(\mathrm{~V})$ is Ig-open (or 


\section{Global Proceedings Repository American Research Foundation}

ISSN 2476-017X

Available online at http:// proceedings.sriweb.org

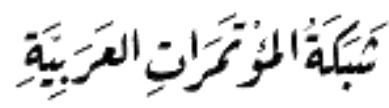

http://arab.kmshare.net/

Ig-closed) set in $\mathrm{X}$ of every $\mathrm{T}^{*}$-Ig-open set (or $\mathrm{T}^{*}$-Ig-closed set) in $\mathrm{Y}[11]$. A map $f:(X, T) \rightarrow(Y, \tau)$ is called contra $T^{*}$ generalized-continuous(contra $T^{*}$-Ig-continuous ) if the inverse image of every Ig-open set in $Y$ is $T^{*}$-Ig-closed set in $X[12]$. A map $\mathrm{f}:(\mathrm{X}, \mathrm{T}) \rightarrow(\mathrm{Y}, \tau)$ is called perfectly $\mathrm{T}^{*}$ generalized-continuous(perfectly $\mathrm{T}^{*}$-Igcontinuous ) if $\mathrm{f}^{-1}(\mathrm{~V})$ is both Ig-open and Ig-closed set in $\mathrm{X}$ for every is $\mathrm{T}^{*}$-Ig-closed set $\mathrm{V}$ in $\mathrm{Y}[11]$.

map $\mathrm{f}:(\mathrm{X}, \mathrm{T}) \rightarrow(\mathrm{Y}, \tau)$ is called totally $\mathrm{T}^{*}$ generalized-continuous(totally $\mathrm{T}^{*}$-Igcontinuous ) if $\mathrm{f}^{-1}(\mathrm{~V})$ is $\mathrm{T}^{*}$-Ig-clopen set in $\mathrm{X}$ for every Ig-open set $\mathrm{V}$ in $\mathrm{Y}$ [12]. $\mathrm{A}$ map $f:(X, T) \rightarrow(Y, \tau)$ is called perfectly irresolute if $f^{-1}(V)$ is both Isemi-open and Isemi-closed set in $\mathrm{X}$ for every is Isemi-closed set $\mathrm{V}$ in $\mathrm{Y}[9]$. A map $\mathrm{f:}(\mathrm{X}, \mathrm{T}) \rightarrow(\mathrm{Y}, \tau)$ is called perfectly contra-irresolute if $\mathrm{f}^{-1}(\mathrm{~V})$ is both Isemi- open and Isemi-closed set in $\mathrm{X}$ for every is Isemi-open set $\mathrm{Vin} \mathrm{Y}$ [2]. map $\mathrm{f}: \mathrm{X} \rightarrow \mathrm{Y}$ from an intuitionistic topological space $(X, T)$ in to an intuitionistic topological space $(Y, \tau)$ is called perfectly contra semipre-irresolute (resp. perfectly contra semi- irresolute and contra pre- irresolute) (contra Isp- irresolute (resp. contra Is- irresolute and contra Ip -irresolute) function if $\mathrm{f}^{-1}(\mathrm{~V})$ is both Isp-open and Isp-closed(resp.Is-open and Is-closed and Ip-open and Ipclosed )set in $X$ for every Isp-open(resp.Is-open and Ip-open)set $V$ in $Y$ [2] . A map $\mathrm{f}:(\mathrm{X}, \mathrm{T}) \rightarrow(\mathrm{Y}, \tau)$ is called perfectly generalized-irresolute if $\mathrm{f}^{-1}(\mathrm{~V})$ is both Ig-open and Ig-closed set in $\mathrm{X}$ for every is Ig-closed set $\mathrm{V}$ in $\mathrm{Y}$ [2]. A map $\mathrm{f}: \mathrm{X} \rightarrow \mathrm{Y}$ from an intuitionistic topological space $(X, T)$ in to an intuitionistic topological space $(Y, \tau)$ is called contra-continuous if $\mathrm{f}^{-1}(\mathrm{~V})$ is Iclosed set in $\mathrm{X}$ for each Iopen $\mathrm{V}$ set in $\mathrm{Y}$ [4]. Remark 2.1 [10] It has been proved that :Every Iclosed set (Ig-closed and $T^{*}$ Iclosed) set is $T^{*}$-Ig-closed. The complement of $T^{*}$-Ig-closed set is $T^{*}$-Ig-open set.

\section{III- Contra $\mathbf{T}^{*}$ - intuitionistic generalized irresolute maps in Intuitionistic topological spaces \\ I define,in this section anew kinds of $X$ maps called $T^{*}$-intuitionistic irresolute maps, $T^{*}$-intuitionistic generalized irresolute maps, contra $T^{*}$-intuitionistic irresolute and contra $T^{*}$-intuitionistic generalized irresolute maps an intuitionistic topological spaces and related to other kind of maps which are defined in this work.}

I start this section by the following definitions.

Definition 3.1 A map $f:(X, T) \rightarrow(Y, \tau)$, where $(X, T)$ and $(Y, \tau)$ are ITS is called $T^{*}$ - intuitionistic irresolute if the inverse image of every $T^{*}$-Iclosed set in $Y$ is $T^{*}$-Iclosed set in $X$.

Definition 3.2 A map $f:(X, T) \rightarrow(Y, \tau)$, where $(X, T)$ and $(Y, \tau)$ are ITS is called contra $T^{*}$ - intuitionistic irresolute if the inverse image of every $T^{*}$ - Iopen set in $Y$ is $T^{*}$ Iclosed set in $X$.

Definition 3.3 A map $f:(X, T) \rightarrow(Y, \tau)$, where $(X, T)$ and $(Y, \tau)$ are ITS is called $T^{*}$-intuitionistic generalized-irresolute $\left(T^{*}\right.$-Ig-irresolute $)$ if the inverse image of every $T^{*}$-Ig-closed set in $Y$ is $T^{*}$-Ig-closed set in $X$.

Next Iam going to generalize the definition of contra $T^{*}$ - Ig-irreolute for ITS. 


\section{Global Proceedings Repository \\ American Research Foundation}

ISSN 2476-017X

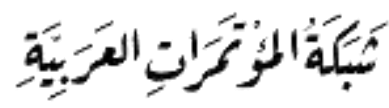

http://arab.kmshare.net/

Available online at http:// proceedings.sriweb.org

Definition 3.4 A map $f:(X, T) \rightarrow(Y, \tau)$, where $(X, T)$ and $(Y, \tau)$ are ITS is called contra $T^{*}$-intuitionistic generalized-irresolute (contra $T^{*}$-Ig-irresolute) if the inverse image of every $T^{*}$-Ig-open set in $Y$ is $T^{*}$-Ig-closed set in $X$.

The following characterization can be proved in the following proposition.

Proposition 3.5 Amapping $f: X \rightarrow Y$ from an intuitionistic topological space $\left(X, T^{*}\right)$ in to an intuitionistic topological space $\left(Y, \tau^{*}\right)$ is contra $T^{*}$ - Ig-irresolute if and only if the inverse image of every $T^{*} I g$-closed set in $Y$ is $T^{*}$ - Ig-open set in $X$.

Proof Assume that $f$ is contra $T^{*}$-Ig-irresolute. Let $B$ be any $T^{*} I g$-closed set in $Y$, then $B^{c}$ is $T^{*} I g$-open set in $Y$. Since $f$ is contra $T^{*}$-Ig-irresolute, $f^{-1}\left(B^{c}\right)$ is $T^{*}$-Igclosed set in $X$. But $f^{-1}\left(B^{c}\right)=\left(f^{-1}(B)\right)^{c}$ and so $f^{-1}(B)$ is $T^{*}$-Ig-open set in $X$. Hence the inverse image of every $T^{*}$-Ig-closed set in $Y$ is $T^{*}$-Ig-open set in $X$.

Assume that the inverse image of every is $T^{*}$-Ig-closed set in $Y$ is $T^{*}$-Ig-open set in $X$. Let $B$ be any $T^{*}$ - Ig-open set in $Y$, then $B^{c}$ is $T^{*}$-Ig-closed set in $Y$. By assumption, $f^{-1}\left(B^{c}\right)$ is $T^{*}$-Ig-open set in $X$. But $f^{-1}\left(B^{c}\right)=\left(f^{-1}(B)\right)^{c}$ and so $f^{-1}(B)$ is $T^{*}$-Igclosed se in $X$. Therefore $f$ is contra $T^{*}$-Ig-irresolute.

The following proposition illustrates the relation between strongly $T^{*}$-Ig-continuous and contra $T^{*}$-Ig-irresolute.

Proposition 3.6 Amapping $f: X \rightarrow Y$ from an intuitionistic topological space $\left(X, T^{*}\right)$ in to an intuitionistic topological space $\left(Y, \tau^{*}\right)$ is strongly $T^{*}$ - Ig-continuous then it is contra $T^{*}$-Ig-irresolute.

Proof Let $f: X \rightarrow Y$ be strongly $T^{*}$ - Ig-continuous. Let A be a $T^{*}$-Ig-open set in $Y$. Since $f$ is strongly $T^{*}$ - Ig-continuous, then $f^{-1}(A)$ is Ig-closed set in $X$. By remark 2.1, $f^{-1}(A)$ is $T^{*}$-Ig-closed set in $X$. Hence fis contra $T^{*}$-Ig-irresolute .

The converse of the a bove proposition need not be true as the following example shows.

Example 3.7 Let $X=\{1,2,3\} ; T=\{\widetilde{\emptyset}, \tilde{X}, A, B\}$ where $A=<x,\{2\},\{1,3\}>$ and $B=<$ $x,\{2\}, \emptyset,>$ Let $Y=\{a, b, c\} ; \Psi=\{\widetilde{\varnothing}, \tilde{Y}, C\}$ where $C=\langle y,\{a\}, \emptyset>$

. Define a mapping $f: X \rightarrow Y$ by $f(2)=a, f(3)=b$ and $f(1)=c$. I can see that $f$ is $T^{*}-I g$ irresolute, Since $C$ is is $T^{*}$-Ig-open set in $Y$, then $B=f^{-1}(C)=<x,\{2\}, \emptyset>T^{*}-I g$ closed set in $X$. Becouse the only $T^{*}$ in $X$ that contain $B$ is $B$ and $Q_{4}=\langle x,\{2,3\}, \emptyset\rangle$ ,then $I \mathrm{cl}^{*} B=B \subseteq B$ and $Q_{4}$. But $f$ is not strongly $T^{*}$ - Ig-continuous, becouse $B=f^{-1}(C)$ is not Ig-closed set in $X$, since the only IOS in X such that $B \subseteq B$ then IclB $=X \subsetneq B$.

In the following result I prove that contra $T^{*}$-irresolute. gives contra $T^{*}$-Ig-irresolute.

Proposition 3.8 Amapping $f: X \rightarrow Y$ from an intuitionistic topological space $\left(X, T^{*}\right)$ in to an intuitionistic topological space $\left(Y, \tau^{*}\right)$ is contra $T^{*}-I$ irresolute then it is contra $T^{*}$-Ig-irresolute.

Proof Let $f: X \rightarrow Y$ be contra $T^{*}$-irresolute. Let $B$ be any $T^{*}$-Iopen set in $Y$. Since $f$ is contra $T^{*}$ - irresolute, then $f^{-1}(B)$ is $T^{*}$-Iclosed set in $X$. By remark $2.1, f^{-1}(B)$ is $T^{*}$-Ig-closed set in $X$ Hence fis contra $T^{*}$-Ig-irresolute .

The converse of the a bove proposition need not be true as the following example shows. 


\section{Global Proceedings Repository \\ American Research Foundation}

ISSN 2476-017X

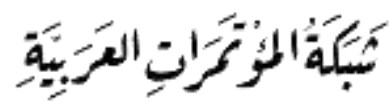

http://arab.kmshare.net/

Available online at http:// proceedings.sriweb.org

Example 3.9 Let $X=\{a, b, c\} ; T=\{\widetilde{\emptyset}, \tilde{X}, A, B, C\}$ where $A=<x,\{c\},\{a, b\}>, B=<$ $x,\{a\}\{b, c\}>$ and $c=<x,\{a, c\},\{b\}>$.Let $Y=\{1,2,3\} ; \Psi=\{\widetilde{\varnothing}, \tilde{Y}, D\}$ where $D=<$ $y,\{1\}, \varnothing>$. Define a mapping $f: X \rightarrow Y$ by $f(a)=1$ and $f(b)=f(c)=2$. It is easy to see that $f$ is contra $T^{*}$-Ig-irresolute, Since $E=<y,\{3\},\{1\}>$ is $T^{*}$-Iopen set in $Y$, then $f^{-1}(E)=<x, \emptyset,\{a\}>\notin T^{*}$-Iclosed set in $X$, so $f$ is not contra $T^{*}$-irresolute but $f$ is contra $T^{*}$-Ig-irresolute Since $E$ is is $T^{*}$-Ig-open set in $Y$ and $f^{-1}(E)$ is $T^{*}$-Ig-closed set in $X$, becouse the only $T^{*}$ in $X$ that contain $Z_{1}=\langle x,\{c\},\{a\}\rangle, Z_{2}=\langle x,\{a, c\}, \varnothing\rangle$ and $Z_{3}=<x,\{c\}, \emptyset>$ then $I c l^{*} f^{-1}(E)=f^{-1}(E) \subseteq Z_{1}, Z_{2}$ and $Z_{3}$.

The following proposition proved that the composition of contra $T^{*}$-Ig-continuous and contra $T^{*}$-Ig-irresolute is also contra $T^{*}$-Ig-continuous.

Proposition 3.10 If a mapping $f: X \rightarrow Y$ is contra $T^{*}$-I $g$-continuous and a mapping $g: Y \rightarrow Z$ is contra $T^{*}$-I $g$-irresolute then the composition $g \circ f: X \rightarrow Z$ is contra $T^{*}$-Igcontinuous.

Proof Let A be any Ig-open set in Z. Since $g$ is contra $T^{*}$-Ig-continuous, $g^{-1}(A)$ is $T^{*}$-Ig-closed set in $Y$. Since $f$ is contra $T^{*}$-Ig-irresolute,$f^{-1}\left(g^{-1}(A)\right)$ is $T^{*}$ II -closed set in X. By remark 2.1, So $f^{-1}\left(g^{-1}(A)\right)$ is $T^{*}$-Ig-closed set. But $f^{-1}\left(g^{-1}(A)\right)=$ $(g \circ f)^{-1}(A)$. Therefore $g \circ f$ is contra $T^{*}$-Ig-continuous.

The following proposition puts a necessary condition on perfectly Ig-continuous to be contra $T^{*}$-Ig-irresolute.

Proposition 3.11 Amapping $f: X \rightarrow Y$ from an intuitionistic topological space $\left(X, T^{*}\right)$ in to an intuitionistic topological space $\left(Y, \tau^{*}\right)$ is perfectly Ig-continuous then it is contra $T^{*}$-Ig-irresolute.

Proof Let $f: X \rightarrow Y$ be perfectly Ig-continuous. Let $A$ be a Ig-open set in $Y$. Since $f$ is perfectly Ig-continuous, then $f^{-1}(A)$ is both Iopen and Iclosed set in $X$. By remark 2.1, $A$ is $T^{*}$-Ig-open and since every Iclosed set is $T^{*}$-Ig-closed set,$f^{-1}(A)$ is $T^{*}$-Igclosed set. Hence fis contra $T^{*}$-Ig-irresolute .

The converse of the a bove proposition need not be true as the following example shows.

Example 3.12 Let $X=\{1,2,3\} ; T=\{\widetilde{\varnothing}, \tilde{X}, A, B\}$ where $A=\langle x,\{3\},\{1,2\}\rangle A=\langle x,\{2\},\{1,3\}\rangle$ and $B=<x,\{3\}, \emptyset>$. Let $Y=\{a, b, c\}, \Psi=\{\widetilde{\varnothing}, \tilde{X}, C\}$ where $C=\{y,\{b\}, \varnothing>$. De fine amapping $f: X \rightarrow Y$ by $f(3)=b, f(2)=a$ and $f(1)=c$. It is easy to see that $f$ is contra $T^{*}$-Ig-irresolute. Since $\beta_{1}=<y,\{b\},\{a\}>$ is $T^{*}$-Ig open set in Y,then $\partial_{2}=f^{-1}\left(\beta_{1}\right)=<x,\{3\},\{2\}>$

$T^{*} I g$ - closed set in $X$, becouse the only $T^{*}$ that contain $\partial_{2}$ is $B, \partial_{2}, \partial_{3}=<x,\{1,3\}, \emptyset>$ and $\partial_{5}=<x,\{2,3\}, \emptyset>$ then $I c l^{*} \partial_{2}=\partial_{2} \subseteq B, \partial_{2}$, $\partial_{3}$ and $\partial_{5}$, but $f$ is not perfectly Ig - continuous. Since $\beta_{1}$ is Ig open set in $Y$, but $\partial_{2}=f^{-1}\left(\beta_{1}\right)$ is not Iopen and Iclosed set in $X$.

Remark 3.13 The following example shows that contra $T^{*}$-Ig-irresolute map in ITS is independent from contra( Isp-irresolute, Isg-irresolute, Ips-irresolute, Ipreirresolute, Igs-irresolute, Igsp-irresolute Ipsg-irresolute and Igps-irresolute)maps.

I start with example showing that:

1) contra $T^{*}$-Ig-irresolute, but not contra Isp-irresolute.

2) contra $T^{*}$-Ig-irresolute, but not contra Ipre-iresolute. 


\section{Global Proceedings Repository}

American Research Foundation

ISSN 2476-017X

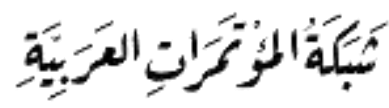

http://arab.kmshare.net/

Available online at http:// proceedings.sriweb.org

Example 3.14 Let $X=\{a, b, c\}$;

$T=\{\widetilde{\emptyset}, \tilde{X}, A\}$ where $A=<x,\{a\},\{b, c\}>$, Let $Y=\{1,2,3\} ; \Psi=$ $\{\widetilde{\varnothing}, \tilde{Y}, C, D\}$ where $C=<y,\{1\},\{2\}>$ and $D=<y,\{1,3\}, \emptyset>$ . Define a mapping $f: X \rightarrow Y$ by $f(a)=1, f(b)=f(c)=3$

$I S P O X=I P O X=T \cup\{B, E, F, R, H, I, J, K, L, M, N, P, Q, S, V\}_{\text {where }} B=$ $\langle x,\{a\}, \emptyset\rangle ; E=\langle x,\{a, c\}, \emptyset\rangle ; F=\langle x,\{a, c\},\{b\}\rangle ; R=$ $\langle x,\{a, b\}, \emptyset\rangle ; H=\langle x,\{b\}, \emptyset\rangle ; I=\langle x,\{c\}, \emptyset\rangle ; J=\langle x, \emptyset,\{b, c\}\rangle ; K=$ $\langle x, \emptyset,\{b\}\rangle ; L=\langle x,\{b\},\{c\}\rangle ; M=\langle x, \emptyset,\{c\}\rangle ; N=\langle x,\{c\},\{b\}\rangle ; P=$ $\langle x,\{b, c\}, \emptyset\rangle ; Q=\langle x,\{a, b\},\{c\}\rangle ; S=\langle x,\{a\},\{b\}\rangle$ and $V=\langle x,\{a\},\{c\}\rangle$. $I S P O Y=I P O Y=\Psi \cup\left\{Q_{i}\right\}_{i=1}^{17}$ where $Q_{1}=\langle y,\{1\}, \emptyset\rangle ; Q_{2}=$ $\langle y,\{1\},\{3\}\rangle ; Q_{3}=\langle y\{1\},\{2,3\}\rangle ; Q_{4}=\langle y,\{1,3\},\{2\}\rangle ; Q_{5}=$ $\langle y,\{2,3\}, \emptyset\rangle ; Q_{6}=\langle y,\{2,3\},\{1\}\rangle ; Q_{7}=\langle y,\{2\}, \emptyset\rangle ; Q_{8}=$ $\langle y,\{2\},\{3\}\rangle ; Q_{9}=\langle y,\{1,2\}, \emptyset\rangle ; Q_{10}=\langle y,\{1,2\},\{3\}\rangle ; Q_{11}=$ $\langle y,\{3\}, \emptyset\rangle ; Q_{12}=\langle y,\{3\},\{1\}\rangle ; Q_{13}=\langle y,\{3\},\{2\}\rangle ; Q_{14}=$ $\langle y,\{3\},\{1,2\}\rangle, Q_{15}=\langle y, \emptyset,\{2\}\rangle ; Q_{16}=\langle y, \emptyset,\{3\}\rangle$ and $Q_{17}=$ $\langle y, \emptyset,\{2,3\}\rangle$, from all above and definition of contra $T^{*}$-Ig-irresolute function that $f$ is contra $T^{*}$-Ig-irresolute. Since $C$ is $T^{*}$-Ig-open set in $Y$, then $B=f^{-1}(C)=<x,\{a\}, \emptyset>$ is $T^{*}$-Ig-closed set in $X$, the only $T^{*}$ in $X$ that contain $B$ is $B$, then I $c^{*} B=B \subseteq B$. But $f$ is not contra Isp-irresolute and not Ipre-irresolute. Since ISPOX and IPOX in X,then Iint Icl I int $B=X \subsetneq B$ and Icl Iint $B=X \subsetneq B$.

I show in this example that there is a functions $f$ such that: 1) $f$ is contra Igs-irresolute and not contra $T^{*}$-Ig-irresolute.

2) $f$ is contra Igsp-irresolute and not contra $T^{*}$-Ig-irresolute.

3) $f$ is contra Isp-irresolute and not contra $T^{*}$-Ig-irresolute.

Example 3.15 Let $X=\{a, b, c\} ; T=\{\widetilde{\emptyset}, \tilde{X}, A, B, C\}$ where $A=<$ $x,\{c\},\{a, b\}>, B=<x,\{a\},\{b, c\}>, C=<x,\{a, c\},\{b\}>$ . Let $Y=\{1,2,3\} ; \Psi=\{\widetilde{\varnothing}, \tilde{Y}, D, E, F\}$ where $D=<y,\{1,3\},\{2\}>, E=<$ $y,\{2\},\{3\}>$ and $F=<y, \emptyset,\{2,3\}>$. Define a mapping $f: X \rightarrow Y$ by $f(c)=2, f(a)=f(b)=3$. ISPOX $=T \cup\left\{Z_{i}\right\}_{i=1}^{19}$ where $Z_{1}=\langle x,\{c\},\{a\}\rangle ; Z_{2}=$ $\langle x,\{a, c\}, \emptyset\rangle ; Z_{3}=\langle x,\{c\},\{b\}\rangle ; Z_{4}=\langle x,\{a\},\{c\}\rangle ; Z_{5}=$ $\langle x,\{a, b\},\{c\}\rangle ; Z_{6}=\langle x,\{c\}, \emptyset\rangle ; Z_{7}=\langle x,\{b, c\},\{a\}\rangle ; Z_{8}=$ $\langle x,\{a\},\{b\}\rangle ; Z_{9}=\langle x,\{a\}, \emptyset\rangle ; Z_{10}=\langle x\{b, c\}, \emptyset\rangle ; Z_{11}=$ $\langle x,\{a, b\}, \emptyset\rangle ; Z_{12}=\langle x,\{b\}, \emptyset\rangle ; Z_{13}=\langle x,\{b\},\{a\}\rangle ; Z_{14}=$ $\langle x,\{b\},\{c\}\rangle, Z_{15}=\langle x, \emptyset,\{a\}\rangle ; Z_{16}=\langle x, \emptyset,\{b\}\rangle ; Z_{17}=\langle x, \emptyset,\{c\}\rangle ; Z_{18}=$ $\langle x, \emptyset,\{a, b\}\rangle$ and $Z_{19}=\langle x, \emptyset,\{b, c\}\rangle . I S P O Y=\Psi \cup\left\{\beta_{i}\right\}_{i=1}^{21}$ where $\beta_{1}=$ $\langle y,\{1,3\}, \emptyset\rangle ; \beta_{2}=\langle y,\{2\}, \emptyset\rangle ; \beta_{3}=\langle y,\{2\},\{1\}\rangle ; \beta_{4}=$ 


\section{Global Proceedings Repository}

American Research Foundation

ISSN 2476-017X

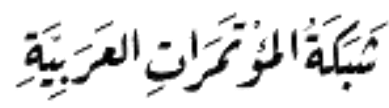

http://arab.kmshare.net/

Available online at http:// proceedings.sriweb.org

$\langle y,\{2\},\{1,3\}\rangle ; \beta_{5}=\langle y,\{2,3\}, \emptyset\rangle ; \beta_{6}=\langle y,\{2,3\},\{1\}\rangle ; \beta_{7}=$ $\langle y,\{1,2\}, \emptyset\rangle ; \beta_{8}=\langle y,\{1,2\},\{3\}\rangle ; \beta_{9}=\langle y, \emptyset,\{1\}\rangle ; \beta_{10}=$ $\langle y, \emptyset,\{2\}\rangle ; \beta_{11}=\langle y, \emptyset,\{3\}\rangle ; \beta_{12}=\langle y, \emptyset,\{1,2\}\rangle ; \beta_{13}=$ $\langle y, \emptyset,\{1,3\}\rangle ; \beta_{14}=\langle y,\{1\}, \emptyset\rangle, \beta_{15}=\langle y,\{1\},\{2\}\rangle ; \beta_{16}=$ $\langle y,\{1\},\{3\}\rangle ; \beta_{17}=\langle y,\{1\},\{2,3\}\rangle, \beta_{18}=\langle y,\{3\}, \emptyset\rangle ; \beta_{19}=$ $\langle y,\{3\},\{1\}\rangle ; \beta_{20}=\langle y,\{3\},\{2\}\rangle$ and $\beta_{21}=\langle y,\{3\},\{1,2\}\rangle$. It is easily to satisfy that $f$ is contra Igs-irresolute( resp. contra Isp-irresolute and contra Igsp-irresolute. But not contra $T^{*}$-Ig-irresolute, since $E$ is $T^{*}-I g$-open set in $Y$, then $A=f^{-1}(E)=<x,\{c\},\{a, b\}>$ that contain $C, Z_{1}, Z_{2}$ and $\operatorname{Icl}^{*} A=<x\{c\},\{a\}>$ is not contained on $A$ or $C$.

Example 3.16 Recall example 3.12 I can get the following:

1) $f$ is contra $T^{*}$-Ig-irresolute, but not contra Isg-irresolute.

2) $f$ is contra $T^{*}$-Ig-irresolute, but not contra Igs-irresolute.

3) fis contra $T^{*}$-Ig-irresolute, but not contra Ipsg-irresolute.

4) $f$ is contra $T^{*}$-Ig-irresolute, but not contra Igps-irresolute.

5) $\mathrm{f}$ is contra $T^{*}$-Ig-irresolute, but not contra Igsp-irresolute.

6) $\mathrm{f}$ is contra $T^{*}$-Ig-irresolute, but not contra Ips-irresolute. ISOX $=I P S O X=T \cup\left\{\partial_{1}, \partial_{2}, \partial_{3}, \partial_{4}, \partial_{5}, \partial_{6}\right\}$ where $\partial_{1}=\langle x,\{3\},\{1\}\rangle ; \partial_{2}=$ $\langle x,\{3\},\{2\}\rangle, \partial_{3}=\langle x,\{1,3\}, \emptyset\rangle ; \partial_{4}=\langle x,\{1,3\},\{2\}\rangle ; \partial_{5}=$ $\langle x,\{2,3\}, \emptyset\rangle$ and $\partial_{6}=$ $\langle x,\{2,3\},\{1\}\rangle . I S O Y=I P S O Y=\left\{\Psi \cup \beta_{1}, \beta_{2}, \beta_{3}\right\}$ where $\beta_{1}=$ $\langle y,\{b\},\{a\}\rangle ; \beta_{2}=\langle y,\{b\},\{c\}\rangle$ and $\beta_{3}=\langle y,\{b\},\{a, c\}\rangle$. Let $C$ is $T^{*}-I g-$ open set in $Y$, then $\quad B=f^{-1}(C)=<x,\{3\}, \emptyset>\quad$ is $\quad T^{*}-I g-$ closed set in $X$. So $f$ is contra $T^{*}$-Ig-irresolute ,but not contra Isgirresolute contra Igs-irresolute contra Igsp-irresolute and contra Ipsirresolute.Since C is Isg-open, Igs-open, Igsp-open, Ipsg-open, Igps-open and Ips-open set in $Y$, then $B=f^{-1}(C)$ is not Isg-cloesd, not Igs-closed not Igsp-closed, not Ipsg-closed, not Igps-closed and not Ips-closed set in X.

In the next example I show that:

1) contra Ips-irresloute function, but not contra $T^{*}$-Ig-irresolute function.

2) contra Ipre-irresolute function, but not contra $T^{*}$-Ig-irresolute function.

Example 3.17 Let $X=\{a, b, c\} ; T=\{\widetilde{\emptyset}, \tilde{X}, A, B\}$ where $A=\langle x,\{c\},\{b\}\rangle$ and $B=<x,\{a, c\}, \emptyset,>$ Let $Y=\{1,2,3\} ; \Psi=\{\widetilde{\varnothing}, \tilde{Y}, C, D, E\}$ where $C=<$ 


\section{Global Proceedings Repository}

American Research Foundation

ISSN 2476-017X

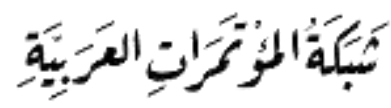

http://arab.kmshare.net/

Available online at http:// proceedings.sriweb.org

$y,\{1,3\},\{2\}>, D=<y,\{2\},\{3\}>$ and $E=<y, \emptyset,\{2,3\}>$

. Define a mapping $f: X \rightarrow Y$ by $f(c)=3$ and $f(b)=f(a)=1$.

IPSOX $=T \cup\left\{Q_{1}, Q_{2}, Q_{3}\right\}$ where $Q_{1}=\langle x,\{c\}, \emptyset\rangle ; Q_{2}=$

$\langle x,\{a, c\},\{b\}\rangle ; Q_{3}=\langle x,\{b, c\}, \emptyset\rangle . I P O X=T \cup\left\{Q_{i}\right\}_{i=4}^{17}$ where $Q_{4}=$

$\langle x,\{c\},\{a\}\rangle ; Q_{5}=\langle x,\{c\},\{a, b\}\rangle ; Q_{6}=\langle x,\{a\}, \emptyset\rangle ; Q_{7}=$

$\langle x,\{a\},\{b\}\rangle ; Q_{8}=\langle x,\{a\},\{c\}\rangle ; Q_{9}=\langle x,\{a\},\{b, c\}\rangle ; Q_{10}=$

$\langle x,\{a, b\}, \emptyset\rangle ; Q_{11}=\langle x,\{a, b\},\{c\}\rangle ; Q_{12}=\langle x,\{b\}, \emptyset\rangle ; Q_{13}=$

$\left\langle x,\{b\},\{a\rangle ; Q_{14}=\langle x, \emptyset,\{a\}\rangle ; Q_{15}=\left\langle x, \emptyset,\{b\rangle ; Q_{16}=\right.\right.$

$\langle x, \emptyset,\{a, b\}\rangle$ and $Q_{17}=\langle x,\{b, c\},\{a\}\rangle$.

$I P O Y=\Psi \cup\left\{K_{i}\right\}_{i=1}^{9}$ where $K_{1}=\langle y,\{1,3\}, \emptyset\rangle ; K_{2}=$

$\langle y,\{2\},\{1,3\}\rangle ; K_{3}=\langle y,\{1,2\}, \emptyset\rangle ; K_{4}=\langle y,\{1,2\},\{3\}\rangle ; K_{5}=$

$\langle y,\{1\}, \emptyset\rangle ; K_{6}=\langle y,\{1\},\{2\}\rangle ; K_{7}=\langle y,\{1\},\{3\}\rangle ; K_{8}=$

$\langle y,\{1\},\{2,3\}\rangle$ and $K_{9}=\langle y, \emptyset,\{3\}\rangle . I P S O Y=\left\{\widetilde{\varnothing}, \widetilde{Y}, C, D, E, K_{1}\right\}$. It is

very easy to see that $f$ is contra Ips-irresolute and contra Ipre-

irresolute .But not contra $T^{*}$-Ig-irresolute, because $D$ is $T^{*}$-Ig-open

set in $Y$, then $f^{-1}(D)=<x, \emptyset,\{c\}>$ that contain $B$, and Icl ${ }^{*}$

$f^{-1}(D)=\langle x,\{b\},\{c\}\rangle \subsetneq B$.

Next I show that:

1) $f$ is contra Ipsg-irresolute, but not contra $T^{*}$-Ig-irresolute.

2) $f$ is contra Igps-irresolute, but not contra $T^{*}$-Ig-irresolute.

3) $f$ is contra Isg-irresolute, but not contra $T^{*}$-Ig-irresolute.

Example 3.18 Let $X=\{a, b, c\} ; T=\{\widetilde{\emptyset}, \tilde{X}, A, B\}$ where $A=<$ $x,\{c\},\{b\}>$ and $B=<x,\{a, c\}, \emptyset>$. Let $Y=\{1,2,3\} ; \Psi=$ $\{\widetilde{\varnothing}, \tilde{Y}, C, D\}$ where $C=<y,\{1,3\}, \emptyset>$ and $D=<y,\{1\},\{3\}>$

. Define a mapping $f: X \rightarrow Y$ by $f(a)=f(b)=1$ and $f(c)=2$.

ISOX $=I P S O X=T \cup\left\{Z_{1}, Z_{2}, Z_{3}\right\}$ where $Z_{1}=\langle x,\{c\}, \emptyset\rangle$

, $Z_{2}=<x,\{a, c\},\{b\}>$ and $Z_{2}=<$

$x,\{b, c\}, \varnothing>. I P S O Y=I S O Y=\Psi \cup\left\{P_{1}, P_{2}, P_{3}\right\}$ where $P_{1}=$

$\langle y,\{1,2\}, \emptyset\rangle ; P_{2}=\langle y,\{1,2\},\{3\}\rangle$ and $P_{3}=\langle y,\{1\}, \emptyset\rangle$. Since $P_{4}=$

$\langle y, \emptyset,\{2,3\}\rangle$ is $T^{*}-I g$-open set in $Y$, then $\bar{Z}_{1}=f^{-1}\left(P_{4}\right)=$

$\langle x, \emptyset,\{c\}\rangle \notin T^{*}-I g$-closed set in $X$, because the only $T^{*}$ in $X$ that contain $B$ is $B$, then I $c^{*} \bar{Z}_{1}=\langle x,\{b\},\{c\}\rangle \subsetneq B$. So f is not contra $T^{*}$ Ig-irresolute, but $f$ is contra Ipsg-irresolute, contra Igps-irresolute and contra Isg-irresolute, since $P_{4}$ is Ipsg-open, Igps-open and Isg-open set in $Y$ and $f^{-1}\left(P_{4}\right)$ is Ipsg-closed, Igps-closed and Ipsgclosed in $X$. 


\section{Global Proceedings Repository}

American Research Foundation

ISSN 2476-017X

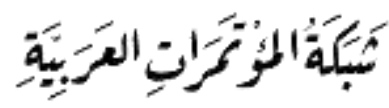

http://arab.kmshare.net/

Available online at http:// proceedings.sriweb.org

The following result I prove that contra Ig-continuous gives contra $T^{*}$-Ig-irresolute.

Proposition 3.19 Amapping $f: X \rightarrow Y$ from an intuitionistic topological space $\left(X, T^{*}\right)$ in to an intuitionistic topological space $\left(Y, \tau^{*}\right)$ is contra Ig-continuous then it is contra $T^{*}$-Ig-irresolute.

Proof Let $f: X \rightarrow Y$ be contra Ig-continuous. Let $A$ be a I-open set in $Y$, then $f^{-1}(A)$ is Ig-closed set in $X$. Since every Iopen set is $T^{*}$ Ig-open set, $A$ is $T^{*}$-Ig-open set in $Y$. By remark $2.1, f^{-1}(A)$ is $T^{*}$ Ig-closed set. Therefore $f$ is contra $T^{*}$-Ig-irresolute .

However the converse is not true as shown by the following example.

Example 3.20 Recall example 3.12 show that $f$ is contra $T^{*}$-Ig-irresolute, but not contra Ig-continuous. Since $C$ is Iopen in $Y$, then $B=f^{-1}(C)$ is not Igclosed set in $X$.

The following proposition illustrates the relation between totally $T^{*}$-Igcontinuous and contra $T^{*}$-Ig-irresolute.

Proposition 3.21 Amapping $f: X \rightarrow Y$ from an intuitionistic topological space $\left(X, T^{*}\right)$ in to an intuitionistic topological space $\left(Y, \tau^{*}\right)$ is totally $T^{*}$-Ig-continuous then it is contra $T^{*}$-Ig-irresolute.

Proof Assume that $f$ is totally $T^{*}$-Ig-continuous. Let $B$ be any Ig-open set in $Y$, then $f^{-1}(B)$ is $T^{*}$-Ig-clopen set in $X$. Since every Ig-open is $T^{*}$ Ig-open, B is $T^{*}$-Ig-open, By remark 2.1, $f^{-1}(B)$ is $T^{*}$-Ig-closed set in $X$. Therefore $f$ is contra $T^{*}$-Ig-irresolute.

The converse of the a bove proposition need not be true as the following example shows.

Example 3.22 Let $X=\{a, b, c\} ; T=\{\widetilde{\varnothing}, \tilde{X}, A, B, C\}$ where $A=<$ $x,\{a, b\},\{c\}>, B=<x,\{b, c\},\{a\}>$ and $C=<x,\{b\},\{a, c\}>$. Let $Y=\{1,2,3\} ; \Psi=\{\widetilde{\varnothing}, \tilde{Y}, D, E\}$ where $D=<y,\{1,3\}, \emptyset>$ and $E=<y,\{1\},\{2\}>$. Define a mapping $f: X \rightarrow Y$ by $f(a)=f(c)=3$ and $f(b)=2$. Let $F=\langle y,\{3\},\{2\}\rangle$ is $T^{*}-I g$-open set in $Y$, then $f^{-1}(F)=\langle x,\{a, c\},\{b\}\rangle$ is $T^{*}$-Ig-closed set in $X$, since the only $T^{*}$ in $X$ that contain $X$ only. So f is contra $T^{*}$-Ig-irresolute, but not totally $T^{*}$-Ig-continuous, since $F$ is Ig-open set in Y.Then $f^{-1}(F)$ is asubset $T^{*}$ in $X$ is $\bar{C}$ then $I c^{*} f^{-1}(F)=X \subsetneq \bar{C}$. So is $T^{*}$-Ig-closed. But not $T^{*}$-Ig-open set . 


\section{Global Proceedings Repository}

American Research Foundation

ISSN 2476-017X

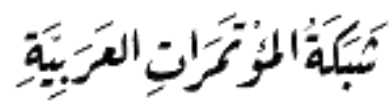

http://arab.kmshare.net/

Available online at http:// proceedings.sriweb.org

I end this section by the following remark .

Remark 3.23 The notions contra $T^{*}$-Ig-irresolute function and $T^{*}$-Igirresolute function in ITS are independent notions. The following examples show the cases.

Example 3.24 Let $X=\{a, b, c\} ; T=\{\widetilde{\emptyset}, \tilde{X}, A, B, C\}$ where $A=<$ $x,\{a, b\},\{c\}>, B=<x,\{b, c\},\{a\}>$ and $C=<x,\{b\},\{a, c\}>$ . Let $Y=\{1,2,3\} ; \Psi=\{\widetilde{\varnothing}, \tilde{Y}, D, E, F\}$ where $D=<y,\{1,3\}, \emptyset>, E=<$ $y,\{2,3\},\{1\}>$ and $F=<y,\{3\},\{1\}>$. Define a mapping $f: X \rightarrow Y$ by $f(a)=f(c)=1$ and $f(b)=3$.I can see that $f$ is $T^{*}$-Ig-irresolute, Let $H=<$ $y,\{1\},\{3\}>$ is $T^{*}$-Ig-closed set in $Y$. Since the only $T^{*}$ in $Y$ that contain $H$ is $D$, then $I c l^{*} H=H \subseteq D$, then $f^{-1}(H)=\langle x,\{a, c\},\{b\}\rangle \subseteq X$ only. But is not $T^{*}$-Ig-open set in $Y$, so f is not contra $T^{*}$-Ig-irresolute .

Example 3.25 Recall example 3.14 it is clear that $f$ is contra $T^{*}$-Igirresolute, but not $T^{*}$-Ig-irresolute, Since $C$ is $T^{*}$-Ig-open set in $Y$. But is not $T^{*}$-Ig-closed set in $Y$.

\section{IV-Perfectly contraT ${ }^{*}$-intuitionistic generalized irresolute map an Intuitionistic topological spaces}

In this section,I introduce a new class of maps called perfectly contra $T^{*}$ intuitionistic generalized irresolute maps which is included in the class of contra $T^{*}$-Ig-irresolute maps. I investigate some basic properties also. And I introduce a new kind of a map forms of intuitionistic irresolute maps and intuitionistic topological spaces namely perfectly contra Ig-irresolute(resp. perfectly contra Igs-irresolute, perfectly contra Ipsg-irresolute, perfectly contra Igps-irresolue, perfectly contra Igsp-irresolute and perfectly contra Isg-irresolute). And illustrate the relation a mong other kinds of perfectly contra $T^{*}$-intuitionistic generalized irresolute maps an intuitionistic topological spaces. As well as I give counter example for not true implications.

I start this section by the following definitions.

Definition 4.1 A map $f:(X, T) \rightarrow(Y, \tau)$, where $(X, T)$ and $(Y, \tau)$ are ITS is called perfectly $T^{*}$ - intuitionistic generalized-irresolute (perfectly $T^{*}$ Ig-irresolute) if the inverse image of every $T^{*}$-Ig-closed set in $Y$ is both $T^{*}$-Ig-open and $T^{*}$-Ig-closed set in X. 


\section{Global Proceedings Repository \\ American Research Foundation}

ISSN 2476-017X

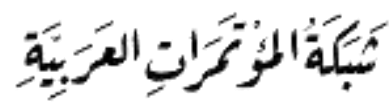

http://arab.kmshare.net/

Available online at http:// proceedings.sriweb.org

Definition 4.2 A map $f:(X, T) \rightarrow(Y, \tau)$, where $(X, T)$ and $(Y, \tau)$ are ITS is called perfectly contra $T^{*}$ - intuitionistic-irresolute (perfectly contra $T^{*}$-irresolute) if the inverse image of every $T^{*}$-Iopen set in $Y$ is both $T^{*}$ Iopen and $T^{*}$-Iclosed set in $X$.

Definition 4.3 A map $f:(X, T) \rightarrow(Y, \tau)$, where $(X, T)$ and $(Y, \tau)$ are ITS is called perfectly contra generalized-irresolute (resp. perfectly contra Igs-irresolute, perfectly contra Isg-irresolute, perfectly contra Ipsgirresolute, perfectly contra Igps-irresolute, and perfectly contra Igspirresolute) function if $f^{-1}(V)$ is both Ig-closed and Ig-open (resp. Igsclosed and Igs-open,Isg-closed and Isg-open, Ipsg-closed and Ipsg-open, Igps-closed and Igps-open, Igsp-closed and Igsp-open) set in X for every Ig-open (resp. Igs-open, Isg-open, Ipsg-open, Igps-open and Igsp-open ) set $V$ in $Y$.

Next Iam going to generalize the definition of perfectly contra $T^{*}$-Igirresolute for ITS.

Definition 4.4 A map $f:(X, T) \rightarrow(Y, \tau)$, where $(X, T)$ and $(Y, \tau)$ are ITS is called perfectly contra $T^{*}$ - intuitionistic generalized-irresolute (perfectly contra $T^{*}$-Ig-irresolute) if the inverse image of every $T^{*}$-Ig-open set in $Y$ is both $T^{*}$-Ig-open and $T^{*}$-Ig-closed set in $X$.

In the following proposition there is characterization an intuitionistic perfectly contra $T^{*}$-Ig-irresolute function.

Proposition 4.5 Amap $f: X \rightarrow$ Yfrom an intuitionistic topological space $\left(X, T^{*}\right)$ in to an intuitionistic topological space $\left(Y, \tau^{*}\right)$ is perfectly contra $T^{*}$-Ig-irresolute if and only if the inverse image of every $T^{*}$-Ig-open set in $Y$ is both $T^{*}$-Ig-closed and $T^{*}$-Ig-open in X.

Proof Assume that $f$ is perfectly contra $T^{*}$-Ig-irresolute. Let $A$ be any $T^{*}$ Ig-open set in $Y$, then $A^{c}$ is $T^{*}$-Ig-closed set in $Y$. Since $f$ is perfectly contra $T^{*}$-Ig-irresolute, $f^{-1}\left(A^{c}\right)$ is both $T^{*}$-Ig-open and $T^{*}$-Ig-closed set in $X$. But $f^{-1}\left(A^{c}\right)=\left(f^{-1}(A)\right)^{c}$ and so $f^{-1}(A)$ is both $T^{*}$-Ig-open and $T^{*}$-Igclosed set in $X$.

Assume that the inverse image of every $T^{*}$-Ig-open set in $Y$ is both $T^{*}$-Igopen and $T^{*}$-Ig-closed, set in $X$. Let $V$ be any $T^{*}$-Ig-closed set in $Y$, then $V^{c}$ is $T^{*}$-Ig-open set in $Y$. By assumption, $f^{-1}\left(V^{c}\right)=\left(f^{-1}(V)\right)^{c}$ and so $f^{-1}(V)$ is both $T^{*}$-Ig-open and $T^{*}$-Ig-closed set in $X$. Therefore $f$ is perfectly contra $T^{*}$-Ig-irresolute . 


\section{Global Proceedings Repository}

American Research Foundation

ISSN 2476-017X

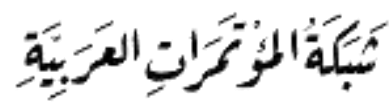

http://arab.kmshare.net/

Available online at http:// proceedings.sriweb.org

The following proposition puts a necessary condition on perfectly contra $T^{*}$-Ig-irresolute to be contra $T^{*}$-Ig-irresolute .

Proposition 4.6 Amapping $f: X \rightarrow Y$ from an intuitionistic topological space $\left(X, T^{*}\right)$ in to an intuitionistic topological space $\left(Y, \tau^{*}\right)$ is perfectly contra $T^{*}$-Ig-irresolute then $f$ is contra $T^{*}$-Ig-irresolute.

Proof Assume that $f$ is perfectly contra $T^{*}$-Ig-irresolute. Let $A$ be any

$T^{*}$-Ig-open set in $Y$, since $f$ is perfectly contra $T^{*}$-Ig-irresolute, $f^{-1}(A)$ is $T^{*}$-Ig-closed set in $X$. Therefore $f$ is contra $T^{*}$-Ig-irresolute .

The converse of proposition is not true in general as the following example shows.

Example 4.7 Recall example 3.22 I can see that $f$ is contra $T^{*}$-Igirresolute, but not perfectly contra $T^{*}$-Ig-irresolute. Becouse $f^{-1}(F)=$ $\langle x,\{a, c\},\{b\}\rangle$ is $T^{*}$-Ig-closed set in $X$, but not $T^{*}$-Ig-open set .

The following proposition gives simple relation between perfectly contra Ig-irresolute and perfectly contra $T^{*}$-Ig-irresolute.

Proposition 4.8 If $f: X \rightarrow Y$ from an intuitionistic topological space $\left(X, T^{*}\right)$ in to an intuitionistic topological space $\left(Y, \tau^{*}\right)$ is perfectly contra Ig-irresolute then it is perfectly contra $T^{*}$-Ig-irresolute.

Proof Let $f: X \rightarrow Y$ be perfectly contra Ig-irresolute. Let $A$ be any Igopen set in $Y$, then $f^{-1}(A)$ is both Ig-closed and Ig-open set in $X$. Since every Ig-open is $T^{*}$-Ig-open set, $A$ is $T^{*}$-Ig-open set in $Y$. By, remark 2.1, $f^{-1}(A)$ is $T^{*}$-Ig-open and $T^{*}$-Ig-closed set in $X$. Therefore $f$ is perfectly contra $T^{*}$ - Ig-irresolute .

The converse of proposition is not true in general as the following example shows.

Example 4.9 Recall example 3.12 since $B=f^{-1}(C)=\langle x,\{3\}, \emptyset\rangle \notin I g$-closed set in $X$, so f is not perfectly contra Ig-irresolute. But $f$ is perfectly contra $T^{*}$ - Ig-irresolute.

The following result I prove that perfectly contra Ig-irresolute gives contra $T^{*}$-Ig-continuous.

Proposition 4.10 Amapping $f: X \rightarrow Y$ from an intuitionistic topological space $\left(X, T^{*}\right)$ in to an intuitionistic topological space $\left(Y, \tau^{*}\right)$ is perfectly contra Ig-irresolute then it is contra $T^{*}$-Ig-continuous.

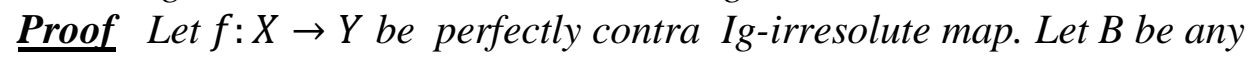
Ig-open set in $Y$. Since $f$ is perfectly contra Ig-irresolute, then $f^{-1}(B)$ is 


\section{Global Proceedings Repository}

American Research Foundation

ISSN 2476-017X

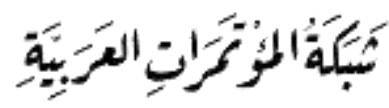

http://arab.kmshare.net/

Available online at http:// proceedings.sriweb.org

both Ig-closed and Ig-open set in X. By remark $2.1, f^{-1}(B)$ is $T^{*}$-Igclosed set in $X$. Hence $f$ is contra $T^{*}$-Ig-continuous .

The converse of the a bove proposition need not be true as the following example shows.

Example 4.11 Recall example 3.22 show that $f$ is contra $T^{*}$-Ig-continuous ,but not perfectly contra Ig-irresolute. Since $F=\langle y,\{3\},\{2\}\rangle$ is Ig-open set in $Y$, then $f^{-1}(F)=\langle x,\{a, c\},\{b\}\rangle$ is not Ig-open set in X. So $f$ is not perfectly contra Ig-irresolute.

The following result I prove that is perfectly contra $T^{*}$-irresolute gives perfectly contra $T^{*}$ - Ig-irresolute.

Proposition 4.12 Amapping $f: X \rightarrow Y$ from an intuitionistic topological space $\left(X, T^{*}\right)$ in to an intuitionistic topological space $\left(Y, \tau^{*}\right)$ is perfectly contra $T^{*}$-irresolute then it is perfectly contra $T^{*}$ - Ig-irresolute.

Proof Let $f: X \rightarrow Y$ be perfectly contra $T^{*}$-irresolute. Let $A$ be any $T^{*}$ Iopen set in $Y$. Since $f$ is perfectly contra $T^{*}$-irresolute, then $f^{-1}(A)$ is both $T^{*}$-Iclosed and $T^{*}$-Iopen set in $X$. By remark $2.1, f^{-1}(A)$ is both $T^{*}$-Ig-closed and $T^{*}$-Ig-open set in $X$. Hence $f$ is perfectly contra $T^{*}$-Igirresolute.

However the converse is not true as shown by the following example.

Example 4.13 Recall example 3.9 it clear that is perfectly contra $T^{*}$ Ig-irresolute, Since $F=\langle y,\{2\},\{3\}\rangle$ is $T^{*}$-Ig-open set in $Y$,then $f^{-1}(F)=\langle x,\{b, c\}, \varnothing\rangle$ is $T^{*}$-Ig-open and $T^{*}$-Ig-closed set in $X$. But $f$ is not perfectly contra $T^{*}$-irresolute, becouse $F \subseteq T^{*}$-Iopen set in $Y$ and $f^{-1}(F)$ is not $T^{*}$-Iclosed and not $T^{*}$-Iopen set in $X$.

Remark 4.14 The following example shows that perfectly contra $T^{*}$ Ig-irresolute map in ITS is independent from perfectly contra( Isp.irresolute, Isg-irresolute, Isemi-irresolute, Ipre-irresolute, Igsirresolute, Igsp-irresolute Ipsg-irresolute and Igps-irresolute) maps. I conclude from this example that :

1) $f$ is perfectly contra $T^{*}$-Ig-irresolute, but not perfectly contra Igs-irresolute .

2) $f$ is perfectly contra $T^{*}$-Ig-irresolute, but not perfectly contra Isg-irresolute.

3) $f$ is perfectly contra $T^{*}$-Ig-irresolute, but not perfectly contra Ipsg-irresolute. 


\section{Global Proceedings Repository}

American Research Foundation

ISSN 2476-017X

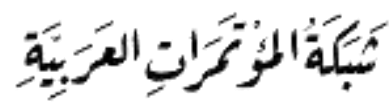

http://arab.kmshare.net/

Available online at http:// proceedings.sriweb.org

4) $f$ is perfectly contra $T^{*}$-Ig-irresolute, but not perfectly contra Igps-irresolute.

5) $f$ is perfectly contra $T^{*}$-Ig-irresolute, but not perfectly contra Igsp-irresolute .

6) $f$ is perfectly contra $T^{*}$-Ig-irresolute, but not perfectly contra Isemi-irresolute .

Example 4.15 Recall example 3.12 I can see that $f$ is perfectly contra $T^{*}$-Ig-irresolute, but $f$ is not perfectly contra Igs-irresolute (resp. perfectly contra Isg-irresolute, perfectly contra Ipsg-irresolute, perfectly contra Igps -irresolute, perfectly contra Igsp-irresolute and perfectly contra Isemi-irresolute). Since C is Igs-open ( resp. Isg-open , Ipsg-open, Igps-open, Igsp-open and Isemi-open) set in Y,then $B=f^{-1}(C)=\langle x,\{3\}, \emptyset\rangle$ is not Igs-closed (resp. Isg-closed, Ipsgclosed, Igps-closed, Igsp-closed and Isemi-closed )set in $X$.

Recall example 3.22 it clear that $f$ is perfectly contra Igs-irresolute, but not perfectly contra $T^{*}$-Ig-irresolute .

Example 4.16 Recall example 3.14 I can get the following :

1) $f$ is perfectly contra $T^{*}$-Ig-irresolute, but not perfectly contra Isp-irresolute .

2) $f$ is perfectly contra $T^{*}$-Ig-irresolute, but not perfectly contra Ipre-irresolute .

It clear that $f$ is perfectly contra $T^{*}$-Ig-irresolute, but $f$ is not perfectly contra Isp-irresolute and perfectly contra Ipre-irresolute . Since ISPOX and IPOX in X, then Iint Icllint $B=X \subsetneq B$ and Icl Iint $B=X \subsetneq B$.

I show in this example that there is afunction $f$ such that:

1) $f$ is perfectly contra Igsp-irresolute, but not perfectly contra $T^{*}$-Igirresolute.

2) $f$ is perfectly contra Isp-irresolute, but not perfectly contra $T^{*}$-Igirresolute.

Example 4.17 Recall example 3.15 from all above and definition of perfectly contra Igsp-irresolute and perfectly contra Isp-irresolute function that $f$ is perfectly contra Igsp-irresolute and perfectly contra Ispirresolute, $f$ is not perfectly contra $T^{*}$-Ig-irresolute, since $E$ is $T^{*}$-Igopen set in $Y$. But its inverse image is not $T^{*}$-Ig-closed set in $X$.

In the next example I show that : 


\section{Global Proceedings Repository}

American Research Foundation

ISSN 2476-017X

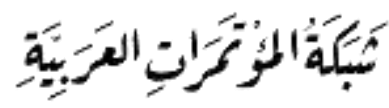

http://arab.kmshare.net/

Available online at http:// proceedings.sriweb.org

1) $f$ is perfectly contra Isg-irresolute, but not perfectly contra $T^{*}$-Igirresolute.

2) $f$ is perfectly contra Ipsg-irresolute, but not perfectly contra $T^{*}$-Igirresolute.

3) $f$ is perfectly contra Igps-irresolute, but not perfectly contra $T^{*}$-Igirresolute.

Example 4.18 Recall example 3.18 I can see that $f$ is perfectly contra Isg-irresolute, perfectly contra Ipsg-irresolute and perfectly contra Igpsirresolute function. Since $P_{4}=\langle y, \emptyset,\{2,3\}\rangle$ is Isg-open, Ipsg-open and Igps-open set in Y,then $\bar{Z}_{1}=f^{-1}\left(P_{4}\right)=\langle x, \emptyset,\{c\}\rangle$ is Isg-closed, Ipsgclosed and Igps-closed set in $X$. But f is not perfectly contra $T^{*}$-Igirresolute.

The following example shows that there is a perfectly contra Isemiirresolute function, which is not perfectly contra $T^{*}$-Ig-irresolute function

Example 4.19 Let $X=\{a, b, c\} ; T=\{\widetilde{\emptyset}, \tilde{X}, A, B, C\}$ where $A=\langle x,\{c\},\{a, b\}>$ $, B=<x,\{a\},\{b, c\}>$ and $C=<x,\{a, c\},\{b\}>$. Let $Y=\{1,2,3\} ; \Psi=$ $\{\widetilde{\varnothing}, \tilde{Y}, D, E\}$ where $D=<y,\{1\},\{2,3\}>$ and $E=<y,\{2,3\},\{1\}>$ . Define a mapping $f: X \rightarrow Y$ by $f(a)=f(b)=3$ and $f(c)=1$. ISOX $=T \cup\left\{R_{1}, R_{2}\right.$ $\left., R_{3}, R_{4}, R_{5}\right\}$ where $R_{1}=\left\langle x,\{c\},\{a\}>, R_{2}=<x,\{a, c\}, \emptyset>, R_{3}=<\right.$ $x,\{b, c\},\{a\}>, R_{4}=<x,\{a\},\{c\}>$ and $R_{5}=<x,\{a, b\},\{c\}>$. ISOY $=\Psi$. It is easily to satisfy that $f$ is perfectly contra Isemi-irresolute, but $f$ is not perfectly contra $T^{*}$-Ig-irresolute, since the only IOS in $T^{*}$ of $X$, that contain $A=f^{-1}(D)=\langle x,\{c\},\{a, b\}\rangle$ is $A$ and $C$, but $I c l^{*} A=\langle x,\{c\},\{a\}\rangle$ is not contained on $A$ or $C$.

In the following example I show perfectly contra Ipre -irresolute function, but not perfectly contra $T^{*}$-Ig-irresolute function .

Example 4.20 Let $X=\{a, b, c\} ; T=\{\widetilde{\varnothing}, \tilde{X}, A, B\}$ where $A=<x,\{a\},\{b\}>$ and $B=<x,\{a, b\}, \emptyset,>$ Let $Y=\{1,2,3\} ; \Psi=\{\widetilde{\varnothing}, \tilde{Y}, C, D, E\}$ where $C=<$ $y, \emptyset,\{1,3\}>, D=<y,\{1\},\{2,3\}>$ and $E=<y,\{1\},\{3\}>$

. Define a mapping $f: X \rightarrow Y$ by $f(a)=1$ and $f(b)=f(c)=3$. IPOX $=T \cup$ $\left\{P_{i}\right\}_{i=1}^{16}$ where $P_{1}=\langle x,\{a\}, \emptyset\rangle ; P_{2}=\langle x,\{a\},\{c\}\rangle ; P_{3}=\langle x,\{a, b\},\{c\}\rangle ; P_{4}=$ $\langle x,\{a, c\}, \emptyset\rangle ; P_{5}=\langle x,\{c\},\{a, b\}\rangle ; P_{6}=\langle x,\{b\}, \varnothing\rangle ; P_{7}=$ $\langle x,\{a, c\},\{b\}\rangle ; P_{8}=\langle x,\{a\},\{b, c\}\rangle ; P_{9}=\langle x,\{b, c\}, \emptyset\rangle ; P_{10}=$ $\langle x,\{b, c\},\{a\}\rangle ; P_{11}=\langle x,\{c\}, \emptyset,\rangle ; P_{12}=\langle x,\{c\},\{a\}\rangle ; P_{13}=$ $\langle x,\{c\},\{b\}\rangle ; P_{14}=\langle x, \emptyset,\{b, c\}\rangle ; P_{15}=\langle x, \emptyset,\{b\}\rangle$ and $P_{16}=\langle x, \emptyset,\{c\}\rangle$. $I P O Y=\Psi \cup\left\{Q_{i}\right\}_{i=1}^{5}$ where $Q_{1}=\langle y,\{2\}, \emptyset\rangle ; Q_{2}=\langle y,\{2\},\{3\}\rangle ; Q_{3}=$ 


\section{Global Proceedings Repository}

American Research Foundation

ISSN 2476-017X

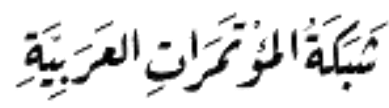

http://arab.kmshare.net/

Available online at http:// proceedings.sriweb.org

$\langle y,\{1,2\}, \emptyset\rangle ; Q_{4}=\langle y,\{1,2\},\{3\}\rangle$ and $Q_{5}=\langle y,\{2,3\}, \emptyset\rangle$.Let $D$ is Ipre-open set in $Y$, then $P_{8}=f^{-1}(D)=<x,\{a\},\{b, c\}>$ is both Ipre-open and Ipreclosed set in $X$. So f is perfectly contra Ipre-irresolute, but not perfectly contra $T^{*}$-Ig-irresolute, because $D$ is $T^{*}$-Ig-open set in $Y$, then $P_{8} \subseteq A, B$, $P_{8}$ and $P_{4}, I c l^{*} P_{8}=\langle x,\{a, c\},\{b\}\rangle \subsetneq A, B$ and $P_{8}$.

The following result I prove that perfectly Ig -continuous gives perfectly contra $T^{*}$-Ig-irresolute .

Proposition 4.21 Amapping $f: X \rightarrow Y$ from an intuitionistic topological space $\left(X, T^{*}\right)$ in to an intuitionistic topological space $\left(Y, \tau^{*}\right)$ is perfectly Ig-continuous then it is perfectly contra $T^{*}$ - Ig-irresolute.

Proof Let $f: X \rightarrow Y$ be perfectly Ig-continuous. Let $A$ be any Ig-open set in $Y$, then $f^{-1}(A)$ is both Iclosed and Iopen set in $X$. Since every Igopen is $T^{*}$-Ig-open set, $A$ is $T^{*}$-Ig-open set in $Y$. By remark $2.1, f^{-1}(A)$ is both $T^{*}$-Ig-closed and $T^{*}$-Ig-open set in X. Hence $f$ is perfectly contra $T^{*}$-Ig-irresolute .

However the converse is not true as shown by the following example.

Example 4.22 Recall example 3.12 I can see that $f$ is perfectly contra $T^{*}$ Ig-irresolute,but not perfectly Ig-continuous. Since C is Ig-open set in $Y$, then $B=f^{-1}(C)$ is Iopen but not Iclosed set in $X$ The following proposition puts a necessary condition on totally $T^{*}$-Igcontinuous to be perfectly contra ${ }^{*}$-Ig-irresolute .

Proposition 4.23 Amapping $f: X \rightarrow Y$ from an intuitionistic topological space $\left(X, T^{*}\right)$ in to an intuitionistic topological space $\left(Y, \tau^{*}\right)$ is totally $T^{*}$-Ig-continuous then $f$ is perfectly contra $T^{*}$-Ig-irresolute.

Proof Assume that $f$ is totally $T^{*}$-Ig-continuous . Let $A$ be any Ig-open set in $Y$. By remark 2.1, A is $T^{*}$-Ig-open set in $Y$. Since $f$ is totally $T^{*}$-Igcontinuous,$f^{-1}(A)$ is $T^{*}$-Ig-clopen set in $X$. Therefore $f$ is perfectly contra $T^{*}$-Ig-irresolute.

The converse of proposition is not true in general as the following example shows.

Example 4.24 Recall example 3.7. I can see that $f$ is perfectly contra $T^{*}$ Ig-irresolute, but not totally $T^{*}$-Ig-continuous . Since $\bar{C}=\langle y, \emptyset,\{a\}\rangle$ is not Ig-open set in $Y$.

I end this section by the following remark. 


\section{Global Proceedings Repository}

American Research Foundation

ISSN 2476-017X

Available online at http:// proceedings.sriweb.org

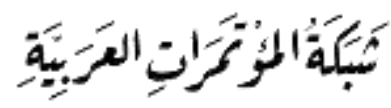

http://arab.kmshare.net/

$\underline{\text { Remark } 4.25}$ The notions perfectly contra $T^{*}$-Ig-irresolute function and perfectly $T^{*}$-Ig-irresolute function in ITS are independent notions. The following examples show the cases.

Example 4.26 Recall example 3.14 it is clear that $f$ is perfectly contra $T^{*}$-Ig-irresolute. Let $C$ is $T^{*}$-Ig-open set in $Y$. then $B=f^{-1}(C)=$ $\langle x,\{a\}, \emptyset\rangle$ is $T^{*}$-Ig-closed and $T^{*}$-Ig-open set in $X$. But is not perfectly $T^{*}$-Ig-irresolute because $C$ is not $T^{*}$-Ig-closed set in Y. Since the only $T^{*}$ in $Y$ that contain $C$ is $C, D$ and $Q_{4}=\langle y,\{1,3\},\{2\}\rangle$, but $I c l^{*} C=$ $\langle y,\{1,2\}, \emptyset\rangle \subsetneq C, D$ and $Q_{4}$.

Example 4.27 Let $X=\{a, b, c\} ; T=\{\widetilde{\emptyset}, \tilde{X}, A, B\}$ where $A=<x,\{c\},\{a, b\}>$ and $B=<x,\{c\}, \varnothing>$ Let $Y=\{1,2,3\} ; \Psi=\{\widetilde{\varnothing}, \tilde{Y}, D, E\}$ where $D=<$ $y,\{1,3\}, \emptyset>$ and $E=<y,\{1\},\{2\}>$ Define a mapping $f: X \rightarrow Y$ by $f(a)=2, f(b)=3$ and $f(a)=1$. I can see that $f$ is perfectly $T^{*}$-Ig-irresolute, but not perfectly contra $T^{*}$-Ig-irresolute. Since $\bar{E}=\langle y,\{2\},\{1\}\rangle$ is $T^{*}$-Igclosed set in $Y$. But is not $T^{*}$-Ig-open set in $Y$.

\section{REFERENCES}

[1] Al-Omari ,A. and Nooroni, M. S.(2009) "On generalized b-closed sets" Bull. Malays. Soc.(2) 32(1), pp.19-30.

[2] Caldas,M. and Jafari, S.(2006) "Weak and strong forms of $\beta$ irresoluteness" The Arabian, J. for sci and E. ,Vol 31, No 1 A, pp. 3139.

[3] Coker, D.(1996) "Anote on intuitionistic sets and intuitionistic points" Tr. J. of Math . 20 , pp. 343-351.

[4] Dontchev, J.(1996) "Contra -continuous functions and strongly S-closed spaces" Int. J. Math. and Math. Sci. Vol. 19 No. 2, pp. 303-310. 


\section{Global Proceedings Repository \\ American Research Foundation}

ISSN 2476-017X

Available online at http:// proceedings.sriweb.org

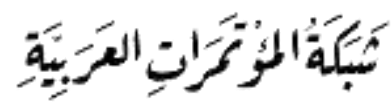

http://arab.kmshare.net/

[5] Dunham, W. (1982) "A new closure operator for non-T $T_{1}$ topologies" kyungpook Math. J. 22, pp. 55-60.

[6] Eswaran, S. and pushpalatha, A. (2009) " $T^{*}$-generalized continuous maps in topological spaces" Int. J. of Math. Sci. and Engineering Applications, Vol. 3, No. IV, (will be published in December 2009 issue).

[7] Levine, N. (1970) "Generalized closed sets in topology" Rend. Circ. Mat. Palermo, 19, 2, pp. 89-96.

[8] Noiri, T. and Popa, V. (2005) "Some properties of a lmost contra-pre continuous functions" Bull. Malays. Moth. Sci. Soc. (2) 28(2), pp. 107116.

[9] Miguel, Caldas , C. (2000) " Weak and strong forms of irresolute " Int. J. Math. Sci. Vol. 23 . No. 4 , pp . 253-259 .

[10] Pushpalatha, A. and Eswaran, S. and Rajar, P. (2009) "T*generalized closed sets in topological spaces" pro. of W. con. on Engineering, I SBN. pp. 978-988.

[11] Pushpalatha, A. and Eswaran, S. (2010) "strongly forms of $\mathrm{T}^{*}$ generalized continuous map in topological spaces" Int. J. contep. Math. Science, Vol. 5, no. 17, pp. 815-822.

[12] Raoof, G. A. and Yaseen , Y. J. (2013) " Contra And Totally $\mathrm{T}^{*} \mathbf{T}^{*}$ - Intuitionistic Generalized - Continuous Maps On Intuitionistic Topological Spaces " Tikrit J. of Pure Sci. 18 (2) , pp . 436-444.

[13] Raoof, G. A. (2008) "On generalized homeomorphism" between ITS" MSC. Tikrit uni. Thesis coll. Of Education.

[14] Santhi , R. and Jayanth, D. (2010)"Contra generalized semipreopen mappings in intuitionistic fuzzy topological spaces" J. of ISSN. 2090-388 X online, Vol. 1,No. 2, pp. 1- 8 .

[15] Sakthivel, K.(2010)"Intuitionistic fuzzy Alpha generalized continuous mappings and intuitionistic Alpha generalized irresolute mappings" A. Math.Sci.,Vol. 4, No. 37, pp. 1831-1842.

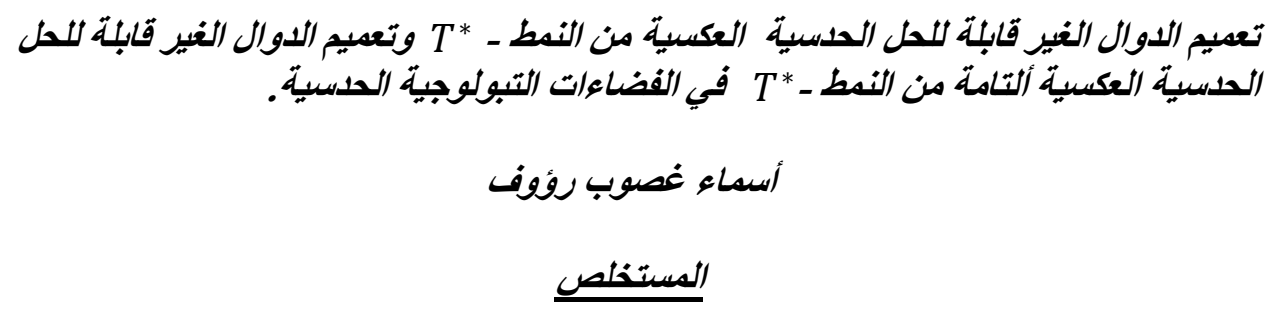




\section{Global Proceedings Repository \\ American Research Foundation}

ISSN 2476-017X

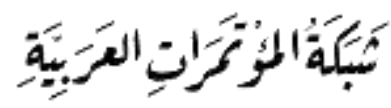

http://arab.kmshare.net/

Available online at http:// proceedings.sriweb.org

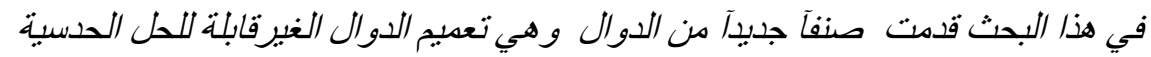

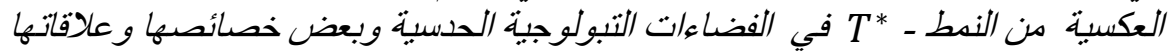

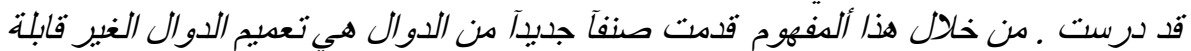

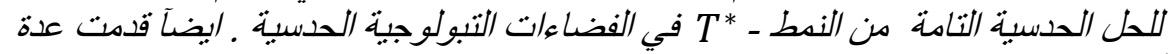

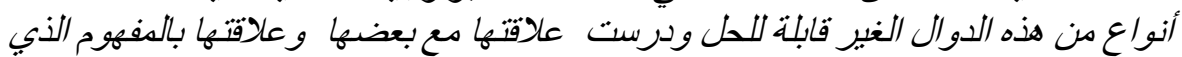
تم دراسته في هذا البحث. 